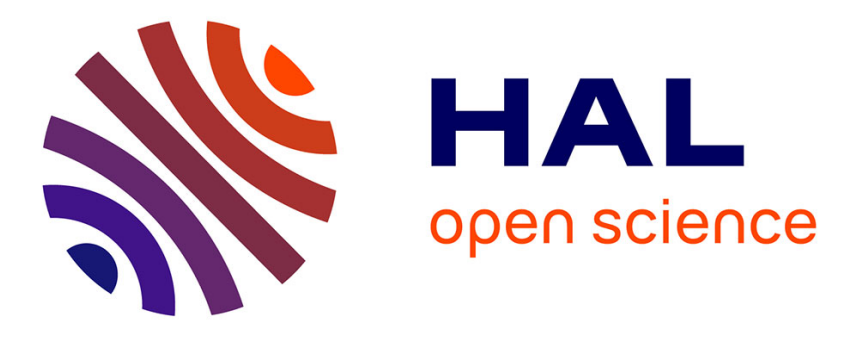

\title{
Ocular adnexal lymphoma and Helicobacter pylori gastric infection
}

Didier Decaudin, Agnès Ferroni, Anne Vincent-Salomon, Kheira Beldjord,

Pierre Validire, Patricia de Cremoux, Patricia Validire, Corine Plancher, Claire Mathiot, Elizabeth Macintyre, et al.

\section{To cite this version:}

Didier Decaudin, Agnès Ferroni, Anne Vincent-Salomon, Kheira Beldjord, Pierre Validire, et al.. Ocular adnexal lymphoma and Helicobacter pylori gastric infection. American Journal of Hematology, 2010, 85 (9), pp.645. 10.1002/ajh.21765 . hal-00599452

\section{HAL Id: hal-00599452 https://hal.science/hal-00599452}

Submitted on 10 Jun 2011

HAL is a multi-disciplinary open access archive for the deposit and dissemination of scientific research documents, whether they are published or not. The documents may come from teaching and research institutions in France or abroad, or from public or private research centers.
L'archive ouverte pluridisciplinaire HAL, est destinée au dépôt et à la diffusion de documents scientifiques de niveau recherche, publiés ou non, émanant des établissements d'enseignement et de recherche français ou étrangers, des laboratoires publics ou privés. 


\section{American Journal of Hematology}

WILEY

\section{Ocular adnexal lymphoma and Helicobacter pylori gastric infection}

\begin{tabular}{|c|c|}
\hline Journal: & American Journal of Hematology \\
\hline Manuscript ID: & AJH-10-0077.R1 \\
\hline Wiley - Manuscript type: & Research Article \\
\hline $\begin{array}{r}\text { Date Submitted by the } \\
\text { Author: }\end{array}$ & 11-May-2010 \\
\hline Complete List of Authors: & $\begin{array}{l}\text { Decaudin, Didier; Institut Curie } \\
\text { Ferroni, Agnès } \\
\text { Vincent-Salomon, Anne } \\
\text { Beldjord, Kheira } \\
\text { Validire, Pierre } \\
\text { de Cremoux, Patricia } \\
\text { Validire, Patricia } \\
\text { Plancher, Corine } \\
\text { Mathiot, Claire } \\
\text { Macintyre, Elizabeth } \\
\text { Asselain, Bernard } \\
\text { Girodet, Jacques } \\
\text { Mal, Frédéric } \\
\text { brousse, Nicole } \\
\text { Beretti, Jean-Luc } \\
\text { Dendale, Rémi } \\
\text { Lumbroso-Le Rouic, Livia } \\
\text { Hermine, Olivier } \\
\text { Lecuit, Marc }\end{array}$ \\
\hline Keywords: & Infectious disease, Non-Hodgkin lymphoma \\
\hline
\end{tabular}

\section{S ScholaroNE" \\ Manuscript Central}




\title{
Ocular adnexal lymphoma and Helicobacter pylori gastric infection
}

\author{
Didier Decaudin ${ }^{1,2}$, Agnès Ferroni ${ }^{3,4}$, Anne Vincent-Salomon ${ }^{5}$, \\ Kheira Beldjord ${ }^{4,6}$, Pierre Validire ${ }^{7}$, Patricia de Cremoux ${ }^{5}$, Patricia Validire ${ }^{1}$, Corine \\ Plancher $^{8}$, Claire Mathiot ${ }^{5}$, Elizabeth Macintyre ${ }^{4,5}$, Bernard Asselain ${ }^{8}$, Jacques \\ Girodet $^{9}$, Frédéric Mal ${ }^{10}$, Nicole Brousse ${ }^{11}$, Jean-Luc Beretti ${ }^{3}$, Rémi Dendale ${ }^{12}$, \\ Livia Lumbroso-Le Rouïc ${ }^{13}$, Olivier Hermine ${ }^{14}$, Marc Lecuit ${ }^{4,15,16,17}$
}

1. Department of Clinical Hematology, Institut Curie, Paris, France.

2. Laboratory of preclinical investigation, Department of Translational Research, Institut Curie, Paris, France.

3. Department of Microbiology, Assistance Publique Hôpitaux de Paris, Necker-Enfants malades Hospital, Paris, France.

4. Paris Descartes University, Paris, France.

5. Laboratory of Molecular Pharmacology, Department of Tumor Biology, Institut Curie, Paris, France.

6. Hematology Laboratory, Assistance Publique Hôpitaux de Paris, Necker-Enfants malades Hospital, France.

7. Department of Pathology, Institut Mutualiste Montsouris, Paris, France.

8. Department of Biostatistics, Institut Curie, Paris, France.

9. Department of Surgery, Institut Curie, Paris, France.

10. Department of Gastroenterology, Institut Mutualiste Montsouris, Paris, France.

11. Department of Pathology, Assistance Publique Hôpitaux de Paris, Necker-Enfants maladies Hospital, Paris, France.

12. Department of Radiotherapy Oncology, Institut Curie, Paris, France.

13. Department of Ophthalmology, Institut Curie, Paris, France.

14. Department of Clinical Hematology, Assistance Publique Hôpitaux de Paris, CNRS UMR 8147, Université René Descartes, Necker-Enfants malades Hospital, Paris, France.

15. Department of Infectious Diseases, Assistance Publique Hôpitaux de Paris, NeckerEnfants malades Hospital, Necker-Pasteur Center for Infectious Diseases, Paris, France

16. Institut Pasteur, Microbes and Host Barriers Group, Paris, France

17. Inserm Avenir U604, Paris, France

Running title: Ocular adnexal lymphoma and gastric Hp infection.

Keywords: Ocular adnexal lymphoma, MALT lymphoma, Helicobacter pylori, infection, lymphomogenesis.

To whom correspondence should be addressed: didier.decaudin@ curie.net

Dr Didier Decaudin, MD, PhD,

Service d'Hématologie Clinique, Institut Curie,

26 rue d'Ulm, 75-248 Paris cedex 05, France.

Phone number: (33) 1.44.32.46.90.

Fax number: (33) 1.53.10.40.11. 


\begin{abstract}
There is a causal association between Helicobacter pylori $(\mathrm{Hp})$ gastric infection and the development of gastric MALT lymphoma. In contrast, the link between $H p$ gastric infection and the development of extra-gastric lymphoma has not been thoroughly investigated. We therefore studied the prevalence of gastric $\mathrm{Hp}$ infection at initial diagnosis of ophthalmologic and non-ophthalmologic extra-gastric lymphoma patients. Three cohorts of patients were studied: a first one of 83 patients with OAL, a second one of 101 patients with extra-ophthalmologic extra-gastric lymphoma, and a third one of 156 control individuals (control) without malignant lymphoma. Gastric Hp infection was investigated by histopathological analysis and $\mathrm{Hp}$-specific PCR assay on gastric biopsy tissue samples. We found gastric $H p$ infection in $37 \mathrm{OAL}$ patients (45\%), in 25 extra-ophthalmologic extra-gastric lymphoma cases (25\%), and in 18 controls individuals $(12 \%)(p<0.0001 \mathrm{OAL} / \mathrm{C}$ and $\mathrm{p}<0.01 \mathrm{OAL} / \mathrm{extra-OAL}$ cases). Gastritis was found in $51 \%$ and $9 \%$ of $H p$-positive and $H p$-negative lymphoma patients, respectively $\left(\mathbf{p}<10^{-4}\right)$. Gastric $H p$ infection only correlated with MALT/LPL lymphoma $(p=0.03)$. There is a significant association between gastric $H p$ infection and MALT/LPL OAL. This suggests a novel mechanism of indirect infection-associated lymphomagenesis whereby chronic local antigen stimulation would lead to the emergence of ectopic B-cell lymphoma.
\end{abstract}




\section{INTRODUCTION}

Growing evidence indicates that a number of lymphomas are associated with chronic antigenic stimulation triggered by microbial pathogens [1]. Helicobacter pylori $(\mathrm{Hp})$ is a widely distributed bacterium that infects the human stomach mucosa and causes chronic active gastritis, leading to peptic ulcer disease, gastric adenocarcinoma, and mucosaassociated lymphoid tissue (MALT) lymphoma [2]. An association between $H p$ infection and gastric MALT lymphomas was first reported in 1991 [3]. Molecular progression from Helicobacter pylori-associated chronic gastritis to MALT gastric lymphoma has since been demonstrated [4], as well as the causal role of $\mathrm{Hp}$ in this process. According to a widely accepted pathophysiological scenario, persistence of gastric $\mathrm{Hp}$ infection leads to chronic and sustained antigen-driven lymphoproliferation, which, coupled with chronic inflammation, may lead to the emergence of allo- and auto-reactive lymphoid clones which proliferation may become antigen-independent in the context of additional oncogenic events by passing $\mathrm{B}$ cell receptor stimulation such as translocation [1-5]. $H p$ now stands as a model microorganism associated with antigen-driven lymphomagenesis. Likewise, a number of other microbial pathogens such as B. burgdorferi, $C$. jejuni or Hepatitis $\mathrm{C}$ virus have since been implicated in microbial antigen- driven lymphomagenesis, also referred as "indirect" lymphomagenesis, as opposed to other microorganisms known to have a direct transforming activity such as the lymphotropic viruses HTLV1, EBV and HHV8 [1].

A new comer in the field of infection-associated lymphoma is the ocular adnexal lymphoma (OAL), which has been reported to be associated with Chlamydia psittaci $(C p)$ ocular infection in around $20 \%$ of the more than 400 OAL biopsy samples analysed until now [6,7]. It has been proposed that $C p$ may play in OAL development the causal role that $H p$ plays in gastric MALT lymphoma, as a source of local chronic and sustained antigen-driven lymphoproliferation. In line with this hypothesis, antimicrobial therapy known to be active 
against $C p$ has been shown to be associated with OAL remission. However, an "antitumoral" efficacy of antimicrobial therapy has also been observed in $C p$-negative OAL patients [8-10], thereby suggesting a possible association of other microbial agents and/or extra-ocular infection with OAL. We therefore investigated the possible association between gastric $H p$ infection and OAL. 


\section{PATIENTS AND METHODS}

\section{Patient selection and characteristics}

Three cohorts of patients were investigated for $H p$ infection, a first one of 83 consecutive primary OAL cases, a second one of 101 consecutive non randomly chosen extraophthalmologic extra-gastric lymphoma patients, all treated at a single centre, the Institut Curie, during the same time frame (1970 to 2007) and whom initial staging included gastroscopy with systematic biopsy performed at the Institut Curie, and a third one of 156 individuals who underwent gastroscopy performed at the Institut Mutualiste Montsouris during the same period for digestive symptoms or anemia without evidence of malignant lymphoma and be used as a control population (control). Staging of the disease included laboratory work-up, CT scan or chest radiography plus abdominal ultrasound scan, and, in most cases, bone marrow biopsy, and the disease at diagnosis was defined according to the Ann Arbor staging system [11]. Apart from the existence of an initial ophthalmologic or extra-ophthalmologic extra-gastric lymphoma, no selection was performed. Patients with classical pathological features associated with gastric $H p$ infection, such as gastric malignant lymphoma or ulcer or cancer, were excluded from each of these groups. In concordance with national practices, no ethics committee was required for this retrospectice study; similarly, no written consent given by the patients were required.

Initial characteristics of the overall lymphoma patients' populations are presented in Table 1. Pathological review was centralized and performed by a single experimented hematopathologist (AVS) according to the WHO classification [12]. Since plasmocytic differentiation is very common in MALT lymphomas, tumor samples came from occular sites, and lymphoplasmocytic lymphoma (LPL) are very rare in ophthalmologic localizations, we pooled MALT and lymphoplasmocytic lymphomas. As a consequence, our pathological 
review showed a majority of MALT/LPL lymphomas among OAL patients (74\%), and as expected for a Western country, a majority of follicular and diffuse large B-cell lymphoma among extra-ophthalmologic extra-gastric NHL patients (25\% and 53\% respectively). For the 83 OAL patients, the site of the ophthalmologic lymphomatous disease was the conjunctiva in 36 patients $(43 \%)$, intra-orbital in 32 patients $(33 \%)$, the lachrymal gland in 10 patients (12\%), and palpebral in 4 cases $(5 \%)$. Bilateral ophthalmologic involvement was observed in 10 patients $(12 \%)$. The 5 -year disease-free survival was $66 \%$ and $62 \%$ for the OAL and the extra-ophthalmologic lymphoma patients, respectively. The 5-year overall survival was $84 \%$ and $77 \%$ for the OAL and the extra-ophthalmologic lymphoma patients, respectively.

\section{Detection of gastric and ophthalmologic Hp infection}

Histopathological diagnosis of $\mathrm{Hp}$ infection was determined using $\mathrm{H} \& \mathrm{E}$ and methyl blue coloration. Hp-specific PCR analysis was performed with total DNA obtained from gastric biopsy samples. Total DNA extraction was performed as previously described [13]. Briefly, total DNA was extracted from four $15 \mu \mathrm{m}$-thick tissue sections from AFA (acetic acid, formalin, ethylic alcohol)-fixed tissue samples obtained at the time of diagnosis, using the QIA amp DNA mini kit (Qiagen, Courtaboeuf, France) and quantified. DNA was stored at $-20^{\circ} \mathrm{C}$ until use. All samples were tested for DNA integrity by PCR using primers amplifying the human GAPDH gene. All samples gave a positive GAPDH signal indicating good DNA preservation in all samples. The quantity and purity of extracted DNA were assessed by measuring the absorbance at 230, 260, and $280 \mathrm{~nm}$ using a NanoDrop ND 1000 spectrophotometer (Wilmington, USA). TaqMan PCR was performed to amplify fragments of the $16 \mathrm{~S}$ rRNA gene of Hp, as previously described [14]. 


\section{Statistical Analysis of HP infection detection}

Correlations between $H p$ infection, histopathological, clinical, and biological characteristics of ophthalmologic and extra-ophthalmologic lymphoma patients, as well as correlation between histopathological and PCR analyses of $H p$ infection were determined using the Chi-square test. Disease-free survival (DFS) was defined from the date of diagnosis to the date of first relapse or death (all causes of death). Overall survival (OS) was defined from the date of diagnosis to the date of death or the date of last follow-up. Survival curves were drawn using the Kaplan-Meier method [15], and the level of significance between various outcomes evaluated using a log-rank test. 


\section{RESULTS}

\section{Detection of gastric Hp infection}

The detection of gastric $H p$ infection was first performed by histopathological analysis for all 156 controls and 119 lymphoma patients, including 51 with OAL, among whom 41 were MALT/LPL OAL, and 68 with extra-ophthalmologic lymphoma. The detection of gastric $H p$ infection was also performed by PCR analysis in all 156 controls and ophthalmologic and non-ophthalmologic lymphoma patients (184 cases). Sixty-five cases had exclusive PCR analysis because of the lack of availability of paraffin embedded gastric tissue at the time of the histopathological analysis. As shown in Table 2, among the 119 lymphoma patients for whom both histopathological and PCR analyses were performed, gastric $H p$ infection was detected in 29/51 cases of OAL patients $(57 \%$; 13 cases with both positive histopathological and PCR analyses, 8 with positive histopathological analysis and negative PCR analysis, and 8 with negative histopathological analysis and positive PCR analysis) and in 22/68 cases of extra-ophthalmologic extra-gastric lymphoma patients (32\%; 10 cases with both positive histopathological and PCR analyses, 6 with positive histopathological analysis and negative PCR analysis, and 6 with negative histopathological analysis and positive PCR analysis) (Figure 1). Among OAL cases, 22/41 MALT/LPL OAL were considered as $\mathrm{Hp+}$ (54\%). The two extra-ophthalmic MALT/LPL lymphoma cases were both negative for gastric $H p$ infection. Among the 7 cases of non-MALT/LPL OAL in whom gastric $H p$ infection was diagnosed, all but 2 cases (both mantle-cell lymphomas) were of low grade (3 follicular lymphomas and 2 lymphocytic lymphomas), excluding the diagnosis of a transformation of MALT/LPL lymphomas in high-grade NHL. Hp detection was negative both histopathologically and by PCR assay in 68/119 lymphoma patients (57\%), among whom 22/51 OAL patients (43\%) and 46/68 extra-ophthalmologic lymphoma patients (68\%). 
Among the 156 controls who underwent a fiberoptic gastroscopy, 15 cases were positive for $H p$-specific PCR detection (histopathological and PCR determinations) (10\%).

We first compared the rate of gastric infection for the three studied patient groups with concordant histopathological and PCR analyses, i.e. 35 OAL patients (13 double positive and 22 double negative), 56 extra-ophthalmologic extra-gastric lymphoma patients (10 double positive and 46 double negative), and 148 controls (10 double positive and 138 double negative), and found a significant difference when comparing OAL patients with histologically and PCR proven gastric $H p$ infection versus control cases $\left(37 \%\right.$ vs $7 \% ; \mathrm{p}<10^{-}$ ${ }^{3}$ ), extra-ophthalmologic extra-gastric lymphoma patients versus controls $(18 \%$ vs $7 \%$; $\mathrm{p}<$ 0.02), and OAL patients versus extra-ophthalmologic extra-gastric lymphoma cases (37\% vs $18 \% ; \mathrm{p}=0.04)$.

Because the strength of the correlation between histopathological and $\mathrm{Hp}$-specific PCR analyses was very high $\left(\mathrm{p}<10^{-4}\right)$, we extended our analyses and included cases with gastric $H p$ infection defined by a positive result for at least one technique. Using this diagnostic criterion, among the 184 patients with lymphoma enrolled in our study, 62 were considered as infected (34\%), in whom 37/83 OAL cases (45\%), 28/61 MALT/LPL OAL patients (46\%), and 25/101 extra-ophthalmologic extra-gastric lymphoma cases (26\%)(Figure 2). Together, these results show a significant higher proportion of gastric $H p$ infection in OAL patients compared to healthy cases $\left(\mathrm{p}<10^{-4}\right)$, in extra-ophthalmologic extra-gastric lymphoma patients versus controls $\left(26 \%\right.$ vs $13 \%$; $\left.\mathrm{p}<10^{-3}\right)$, and in OAL patients versus extraophthalmologic extra-gastric lymphoma cases $\left(\mathrm{p}<10^{-2}\right)$. Similar results were also obtained when comparing patients with MALT/LPL OAL to control cases $\left(\mathrm{p}<10^{-3}\right.$ ) and extraophthalmologic extra-gastric lymphoma patients $\left(\mathrm{p}<10^{-2}\right)$.

Among the 8 OAL patients for whom PCR analysis could be performed on the ophthalmologic lymphoma tissue sample, no $H p$ infection was detected. 


\section{Correlations between gastric Hp infection and patients' characteristics}

The proportion of lymphoma patients (overall cases, OAL patients and extraophthalmologic lymphoma cases) with gastric $H p$ infection was analyzed according to their initial characteristics. On the overall studied population of lymphoma patients (184 cases), and as one would expect, a higher and significant correlation was observed between the detection of gastric $\mathrm{Hp}$ infection and the presence of gastritis lesions as determined by histopathological analysis, namely gastritis in $51 \%$ of $H p$-positive infection cases, whatever the initial lymphoma localization, as compared to gastritis in only $9 \%$ of $\mathrm{Hp}$-negative infection patients $\left(\mathrm{p}<10^{-4}\right)$. A significant correlation of gastric $H p$ infection was also found between MALT/LPL vs non-MALT/LPL lymphomas (44\% and 29\%, respectively) $(\mathrm{p}=0.03)$. In contrast, neither gender, age, presence of B symptoms, PS (performance status) greater than 1, nodal involvement, gastric involvement, extra-nodal involvement greater than 1, advanced stage, bone marrow involvement, elevated ESR level, elevated LDH level, and albumin level lower than $40 \mathrm{~g} / \mathrm{L}$ were more frequently associated with $H p$ gastric infection in both studied populations. In particular, the median age of the three studied populations according to $H p$ status and methodologies were not different. For OAL patients, a bilateral ophthalmologic involvement and a specific ophthalmologic site involvement (intra-orbital, conjunctiva, palpebral, and lachrymal gland) were not associated with a higher rate of gastric $H p$ infection. Moreover, on the overall lymphoma patients' population, the 4 subgroups of patients defined by their International Prognostic Index (IPI) score were not significantly different in their proportion of gastric $H p$ infection. However, when the IPI score was reclassified in 2 groups (0-1-2 vs 3-4-5), a higher proportion of gastric $H p$ infection was detected in the high IPI score group, namely $31 \%$ of cases with an IPI score lower than 3 and $51 \%$ of patients with an IPI score of 3 or more $(\mathrm{p}=0.02)$. Nevertheless, this was not observed in the three subpopulations of OAL patients, MALT/LPL OAL cases, and extra- 
ophthalmologic lymphoma patients. Finally, gastric $H p$ infection detected at the initial diagnosis of lymphoma had no impact on disease-free survival and overall survival of the overall studied population, as well as for OAL and extra-ophthalmologic lymphoma patients (data not shown). 


\section{DISCUSSION}

In this study, we investigated the prevalence of gastric $H p$ infection in patients with either OAL, extra-ophthalmologic lymphoma, or who underwent gastric biopsy for digestive symptoms or anemia and in whom no evidence of malignant lymphoma or gastric ulcerous and cancer was found. We demonstrate a significant association between gastric $H p$ infection and OAL, this association being the highest for MALT/LPL OAL. Our conclusions are based on the use of two control populations: a first one constituted by cases without malignant lymphoma, for whom a $13 \%$ rate of gastric $H p$ positivity was found [16,17]; and a second one of extra-ophthalmologic lymphoma patients who presented classical distribution in the different subtype of lymphomas. Since we have not used an extra-gastric and extraophthalmologic MALT/LPL control population, our data demonstrating that gastric $H p$ infection may play a role in extra gastric OAL may also applied to extra-OAL lymphomagenesis.

It is known that infections may contribute to lymphomagenesis, according to at least two types of mechanisms referred to as direct and indirect lymphoid transformation [1]. Lymphotropic viruses such as Epstein-Barr virus, Human Herpes virus 8, and Human TLymphotrophic virus 1 directly infect a subset of lymphoid cells in which they express viral oncogenes that favour cell transformation. Other microbial species such as Helicobacter pylori [18], Campylobacter jejuni [19], and Borrelia burgdorferi [20], may induce chronic inflammation together with protracted antigenic stimulation inducing chronic lymphoid proliferation and leading to lymphoid transformation indirectly, in the absence of lymphoid infection. In all these situations, inflammation and lymphoid infiltration displaying MALT architecture develop at the primary site of the bacterial infection and therefore lead to lymphoid transformation at this local infection site. In this view, Chlamydia psittaci infection, 
that has been associated with OAL [6], could be one event that induces a local ocular adnexal chronic inflammation, antigenic stimulation and lymphoid infiltration.

From our clinical observation, and for the subset of OAL lymphomas associated with gastric $H p$ infection, we propose the hypothesis of a new mechanism of indirect infectionassociated lymphoid transformation: first, gastric $H p$ infection would constitute a persistent source of antigenic stimulation, leading to chronic gastric inflammation and lymphoid infiltration. Indeed, a highly significant proportion of gastric $H p$ infection is observed in OAL patients, as compared to extra-ophthalmologic lymphoma patients and controls, and gastritis is also significantly associated with OAL. The implication of a chronic gastric inflammation as a first indirect antigen-driven mechanism is also supported by the high rate of gastric $H p$ infection in MALT/LPL OAL than in all other subtypes of OAL. In contrast, we did not detect, in all 8 studied cases, $H p$ DNA into ophthalmologic tumour samples, in agreement with what reported by Ferreri et al. [8], but in contradiction with the recent report by Lee et al [21]. This is also supported by the fact that at least a third of OAL patients exhibit extraophthalmologic lymphoma localization at initial diagnosis, with lymph node involvement in about $15 \%$ to $20 \%$ of cases [22,23], bone marrow involvement in about $10 \%$ of patients [23], and multi-organ involvement ranging between $13 \%$ to $46 \%$ [22-24]. Third, circulating lymphomatous cells would be attracted to the ophthalmic mucosa, and may evolve to overt lymphoma, under the influence of additional mitogenic stimuli. In this view, it is of particular interest to note that OAL frequently occur in the course of ocular chronic inflammation or autoimmune diseases $[8,25]$. These local ocular conditions may indeed lead to the local production of cytokines exerting a chemotactic effect on circulating lymphomatous cells according to classical B-cell homing mechanisms. Ophthalmic $C p$ infection could be one of the factors inducing this local chronic inflammation, and attracting circulating lymphoid cells originating from the gastric mucosa. Importantly, the hypothesis of ocular attraction of $\mathrm{Hp}$ - 
induced gastric lymphoid cells to the inflamed ophthalmic mucosa is also supported by the observation that bilateral ophthalmologic involvement is frequently observed at the diagnosis of OAL (12\% in our series) [26] and that a high rate of patients with bilateral and/or more than one MALT site involvement (i.e. $48 \%$ of cases) have been reported [9]. In line with this scenario, it is striking to note that blepharitis as also been strongly associated with gastric $H p$ infection (90\% as detected by 13C-urea breath test in a large cohort of patients) [27]. Moreover, it has been reported the expression of the B-cell attracting chemokine 1 (CXCL13) in OAL biopsy specimens [27]. In the same way, dissociation of first $H p$ gastric infection and ophthalmologic implantation of activated or lymphomatous cells is in concordance with the lack of efficacy of anti-Hp antibiotic therapy in extra-gastric MALT localizations [9]. Finally, some $H p$ antigens display similarities with autoantigens such as the $\mathrm{H}(+) \mathrm{K}(+)$-ATPase expressed by the gastric epithelium. Whether ionic pumps of the lachrymal glands and the gastric mucosa share common epitopes also deserves further investigation $[1,28]$. A remaining question is the case of MALT lymphoma patients with neither gastric $H p$ nor ophthalmic $C p$ infection. These patients may have been previously treated with antimicrobials with anti-Hp or anti- $C p$ activity inducing false negative results. Alternatively, other microorganisms or autoantigens may also be implicated in OAL lymphomagenesis. It has to be mentioned that the search of Chlamydia psittaci DNA was performed in the 11 tumor samples available among the 83 OAL patients and was negative in all studied cases.

In conclusion, our results demonstrate a strong association between gastric $H p$ infection and MALT/LPL OAL and suggest a new mechanism of indirect infection-associated lymphomagenesis whereby chronic local antigen stimulation would lead to the emergence of ectopic B-cell lymphoma. This observation underlines the role of gastric $H p$ infection in lymphomagenesis and the usefulness of diagnosing and treating this infection in patients with lymphomas. A large prospective epidemiological study would evaluate the impact of gastric 
$H p$ infection on the occurrence of a MALT/LPL lymphoma, whatever its initial localization, and the role of antimicrobial therapy in its prevention and treatment. Furthermore, this new paradigm may apply for other pathogens infected other organs and that induced chronic inflammation and B cell stimulation. 


\section{ACKNOWLEDGMENTS}

The authors thank Gilles Quesnes (Department of Microbiology, Assistance Publique Hôpitaux de Paris, Necker-Enfants malades Hospital, Paris), Céline Campet and Martine Thioux (Laboratory of Molecular Pharmacology, Department of Tumor Biology, Institut Curie, Paris), and Christophe Bovin, Sylvie Luby, and Jean-François Villerez (Department of Pathology, Institut Mutualiste Montsouris, Paris) for their technical assistance. 


\section{REFERENCES}

1. Suarez F, Lortholary O, Hermine O, Lecuit M. Infection-associated lymphomas derived from marginal zone B cells: a model of antigen-driven lymphoproliferation. Blood 2006;107:3034-3044.

2. Wilson KT, Crabtree JE. Immunology of Helicobacter pylori: insights into the failure of the immune response and perspectives on vaccine studies. Gastroenterology 2007;133:288-308.

3. Wotherspoon AC, Ortiz-Hidalgo C, Falzon MR, Isaacson PG. Helicobacter pyloriassociated gastritis and primary B-cell gastric lymphoma. Lancet 1991;338:11751176.

4. Zucca E, Bertoni F, Roggero E, et al. Molecular analysis of the progression from Helicobacter pylori-associated chronic gastritis to mucosa-associated lymphoid-tissue lymphoma of the stomach. N Eng J Med 1998;338:804-810.

5. Farinha P, Gascoyne RD. Molecular pathogenesis of mucosa-associated lymphoid tissue lymphoma. J Clin Oncol 2005;23:6370-6378.

6. Ferreri AJ, Guidoboni M, Ponzoni M, et al. Evidence for an association between Chlamydia psittaci and ocular adnexal lymphoma. J Natl Cancer Inst 2004;96:586594.

7. Decaudin D, Riccardo D, de Cremoux P, et al. Variable association between Chlamydophila psittaci infection and ocular adnexal lymphomas: methodological biases or true geographical variations ? Anticancer Durgs 2008;19:761-765.

8. Ferreri AJM, Ponzoni M, Viale E, et al. Association between Helicobacter pylori infection and MALT-type lymphoma of the ocular adnexa: clinical and therapeutic implications. Hematol Oncol 2006;24:33-37.

9. Grünberger B, Wöhrer S, Streubel B, et al. Antibiotic therapy is not effective in patients infected with Helicobacter pylori suffering from extragastric MALT lymphoma. J Clin Oncol 2006;24:1370-1375.

10. Goebel N, Serr A, Mittelviefhaus H, et al. Chlamydia psittaci, Helicobacter pylori and ocular adnexal lymphoma - Is there an association? The German Experience. Leuk Res 2007;31:1450-1452.

11. Cheson BD, Horning SJ, Coiffier B, et al. Report of an international workshop to standardize response criteria for non-Hodgkin's lymphomas. NCI Sponsored Working Group. J Clin Oncol 1999;42:1271-1278.

12. Harris NL, Jaffe ES, Diébold J, et al. World Health Organization classification of neoplastic diseases of the hematopoietic and lymphoid tissues: report of the clinical advisory committee meeting - Airlie House, Virginia, November 1997. J Clin Oncol 1999; 17:3835-3849.

13. De Cremoux P, Subtil A, Ferreri AJM, et al. Re: Evidence for an association between Chlamydia psittaci and ocular adnexal lymphomas. J Natl Cancer Inst 2006;98:365366.

14. Kobayashi D, Eishi Y, Ohkusa T, et al. Gastric mucosal density of Helicobacter pylori estimated by real-time PCR compared with results of urea breath test and histological grading. J Med Microbiol 2002;51:305-311.

15. Kaplan EL, Meier P. Nonparametric estimation from incomplete observations. J Am Stat Assoc 1958;53:457-481.

16. Kivi M, Tindberg Y. Helicobacter pylori occurrence and transmission: a family affair? Scand J Infect Dis 2006;38:407-417.

17. Lehours P, Yilmaz O. Epidemiology of Helicobacter pylori infection. Helicobacter 2007;12:1-3. 
18. Parsonnet J, Hansen S, Rodriguez L, et al. Helicobacter pylori infection and gastric lymphoma. N Eng J Med 1994;330:1310-1311.

19. Lecuit M, Abachin E, Martin A, et al. Immunoproliferative small intestine disease associated with Campylobacter jejuni. N Engl J Med 2004;350:239-248.

20. Garbe C, Stein H, Dienemann D, Orfanos CE. Borrelia burgdorferi-associated cutaneous B cell lymphoma: clinical and immunohistologic characterization of four cases. J Am Acad Dermatol 1991;24:584-590.

21. Lee S-B, Yang J-W, Kim C-S. The association between cinjunctival MALT lymphoma and Helicobacter pylori. Br J Ophthalmol 2008;92:534-536.

22. Zucca E, Conconi A, Pedrinis E, et al. Nongastric marginal zone B-cell lymphoma of mucosa-associated lymphoid tissue. Blood 2003;101:2489-2495.

23. Decaudin D, de Cremoux P, Vincent-Salomon A, Dendale R, Lumbroso-Le Rouic L. Ocular adnexal lymphoma: a review of clinicopathologic features and treatment options. Blood 2006;108:1451-1460.

24. Raderer M, Wöhrer S, Streubel B, et al. Assessment of disease dissemination in gastric compared with extragastric Mucosa-Associated Lymphoid Tissue Lymphoma using extensive staging: a single-center experience. J Clin Oncol 2006;24:3136-3141.

25. Yeung L, Tsao YP, Chen PY, et al. Combination of adult inclusion conjunctivitis and mucosa-associated lymphoid tissue (MALT) lymphoma in a young adult. Cornea 2004;231:71-75.

26. Meunier J, Lumbroso-Le Rouic L, Vincent-Salomon A, et al. Ophthalmologic and intraocular non-Hodgkin's lymphoma: a large single center study of initial characteristics, natural history, and prognostic factors. Hematological Oncology 2004;22:143-158.

27. Falkenhagen KM, Braziel RM, Fraunfelder FW, Smith JR. B-cells in ocular adnexal lymphoproliferative lesions express B-cell attracting chemokine 1 (CXCL13). Am J Ophthalmol 2005;140:335-337.

28. Saccà SC, Pascotto A, Venturino GM, et al. Prevalence and treatment of Helicobacter pylori in patients with blepharitis. Invest Ophthalmol Vis Sci 2006;47:501-508.

28. Tsai PS, Evans JE, Green KM, et al. Proteomic analysis of human meibomian gland secretions. Br J Ophthalmol 2006;90:372-377.

29. Oken MM, Creech RH, Tormay DC, et al. Toxicity and response criteria of the Eastern Cooperative Oncology Group. Am J Clin Oncol 1982;5:649-655.

30. Carbone PP, Kaplan HS, Musshoff K, Smithers DW, Tubiana M. Report of the committee on Hodgkin's disease staging classification. Cancer Res 1971;31:18601861.

31. No authors listed. A predictive model for aggressive non-Hodgkin's lymphoma. The International Non-Hodgkin's Lymphoma Prognostic Factors Project. N Engl J Med 1993;329:987-994. 


\section{FIGURE LEGENDS}

Figure 1: A. Real time PCR of Hp. Result obtained from a positive sample. B. Chronic gastritis with numerous intraglandular $H p$ (HES, 60x). C. Gastric glands with intraluminal $H p$ (methyl blue, 60x). In both $\mathrm{B}$ and $\mathrm{C}$ figures, $\mathrm{Hp}$ are indicated with red arrows.

Figure 2: Proportion of patients with positive detection of gastric $H p$ infection. 
Table 1: Initial characteristics of the studied populations

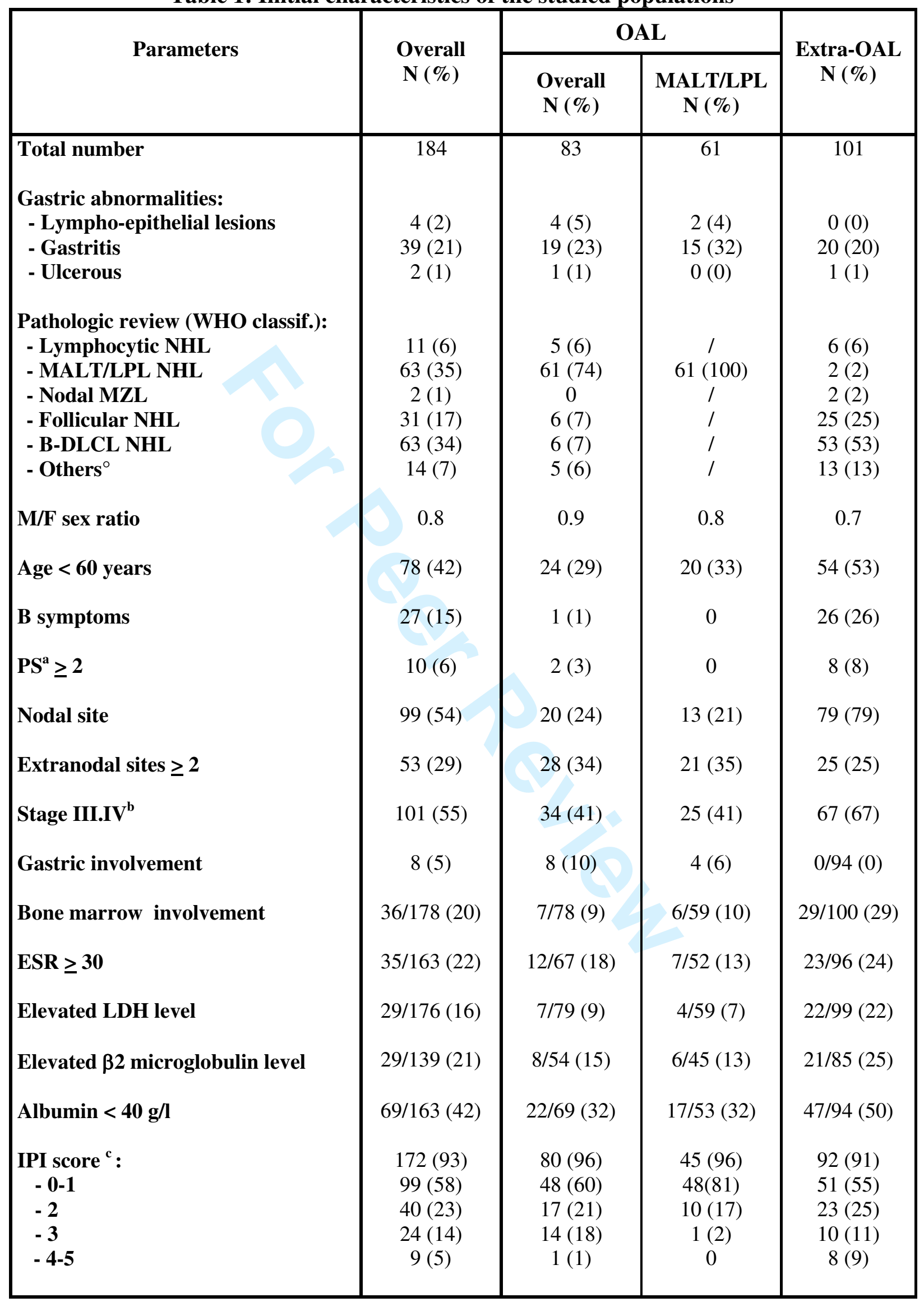




\begin{abstract}
Abbreviations: N, number of cases; pts, patients; OAL, ocular adnexal lymphoma; MZL, marginal zone lymphoma; LPL, lymphoplasmocytic lymphoma; M, male; F; female; PS, performance status; LDH; lactate dehydrogenase; IPI, international prognostic index.

${ }^{\circ}$ Other histopathological sub-type of lymphomas included mantle cell lymphoma, Burkitt's lymphomas, T-lymphoblastic lymphoma, anaplastic T-cell lymphoma, Hodgkin's lymphoma, and unspecified low-grade lymphomas.

${ }^{\mathrm{a}}$ Oken et al [29].

${ }^{\mathrm{b}}$ Carbone et al [30].

${ }^{\mathrm{c}}$ Shipp et al [31].
\end{abstract}


Table 2: Detection of gastric $H p$ infection of the different studied populations

\begin{tabular}{|c|c|c|c|c|c|c|}
\hline & \multicolumn{2}{|c|}{$H p-$} & \multicolumn{4}{|c|}{$\boldsymbol{H p}+$} \\
\hline & $\begin{array}{c}\text { PCR - } \\
\text { Histo NA }\end{array}$ & $\begin{array}{l}\text { PCR - } \\
\text { Histo - }\end{array}$ & $\begin{array}{l}\text { PCR + } \\
\text { Histo + }\end{array}$ & $\begin{array}{l}\text { PCR - } \\
\text { Histo + }\end{array}$ & $\begin{array}{l}\text { PCR + } \\
\text { Histo - }\end{array}$ & $\begin{array}{c}\text { PCR + } \\
\text { Histo NA }\end{array}$ \\
\hline \multirow{2}{*}{$\begin{array}{l}\text { Controls } \\
(\mathrm{N}=156)\end{array}$} & 0 & 138 & 10 & 3 & 5 & 0 \\
\hline & \multicolumn{2}{|c|}{$138(\mathbf{8 8 \%})$} & \multicolumn{4}{|c|}{$18(\mathbf{1 2 \%})$} \\
\hline \multirow{2}{*}{$\begin{array}{c}\text { Extra-OAL } \\
(\mathbf{N}=101)\end{array}$} & 30 & 46 & 6 & 10 & 6 & 3 \\
\hline & \multicolumn{2}{|c|}{$76(\mathbf{7 6 \%})$} & \multicolumn{4}{|c|}{$25(25 \%)$} \\
\hline \multirow{2}{*}{$\begin{array}{c}\text { OAL } \\
(\mathbf{N}=83)\end{array}$} & 24 & 22 & 13 & 8 & 8 & 8 \\
\hline & \multicolumn{2}{|c|}{$46(55 \%)$} & \multicolumn{4}{|c|}{$37(\mathbf{4 5 \%})$} \\
\hline \multirow{2}{*}{$\begin{array}{c}\text { MALT/LPL } \\
\text { OAL }(\mathbf{N}=61)\end{array}$} & 14 & 19 & 10 & 7 & 5 & 6 \\
\hline & \multicolumn{2}{|c|}{$33(54 \%)$} & \multicolumn{4}{|c|}{$28(46 \%)$} \\
\hline
\end{tabular}

Abbreviations: Histo: Histopathological analysis; NA: gastric tissue not available. 


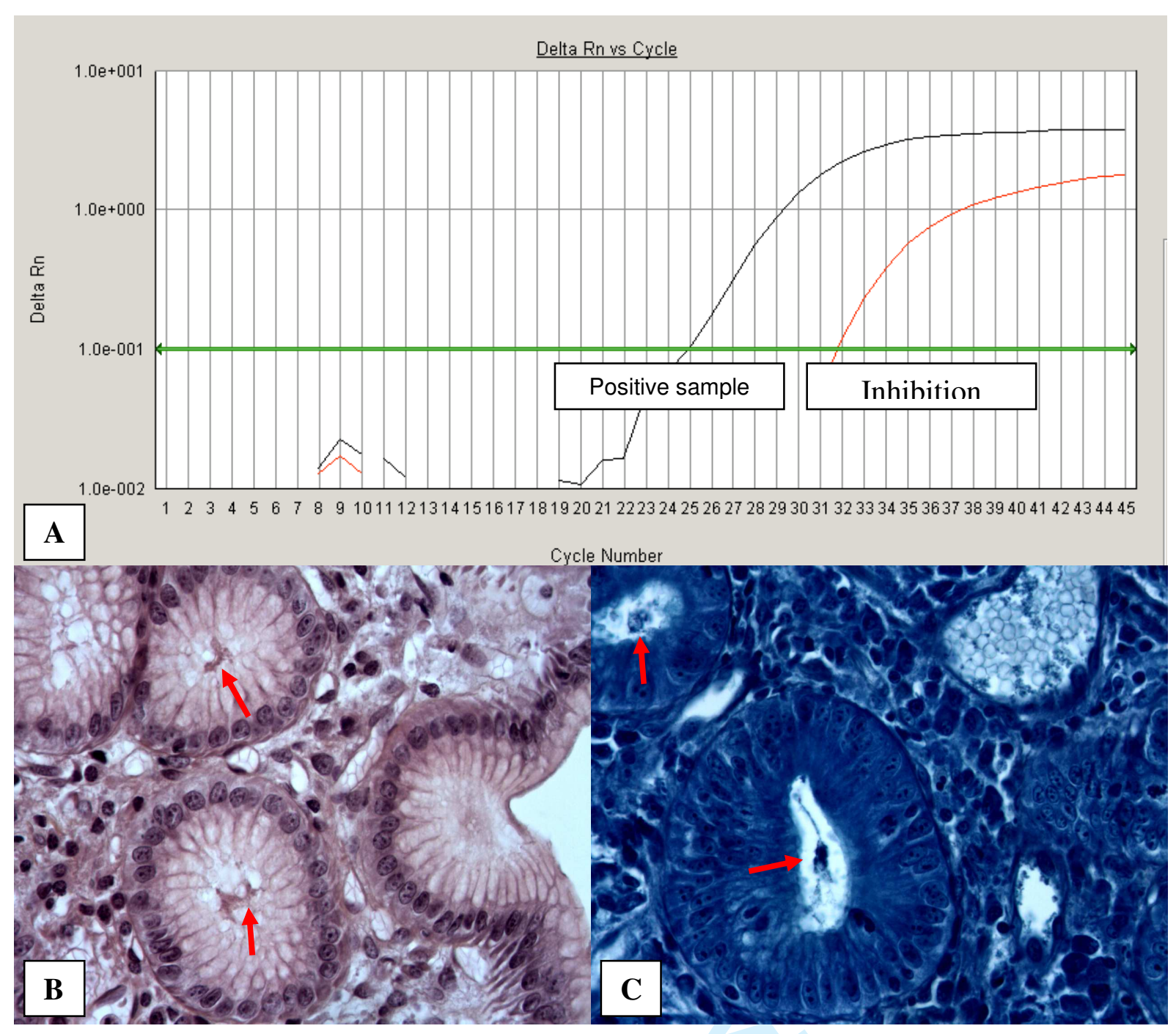


Figure 2

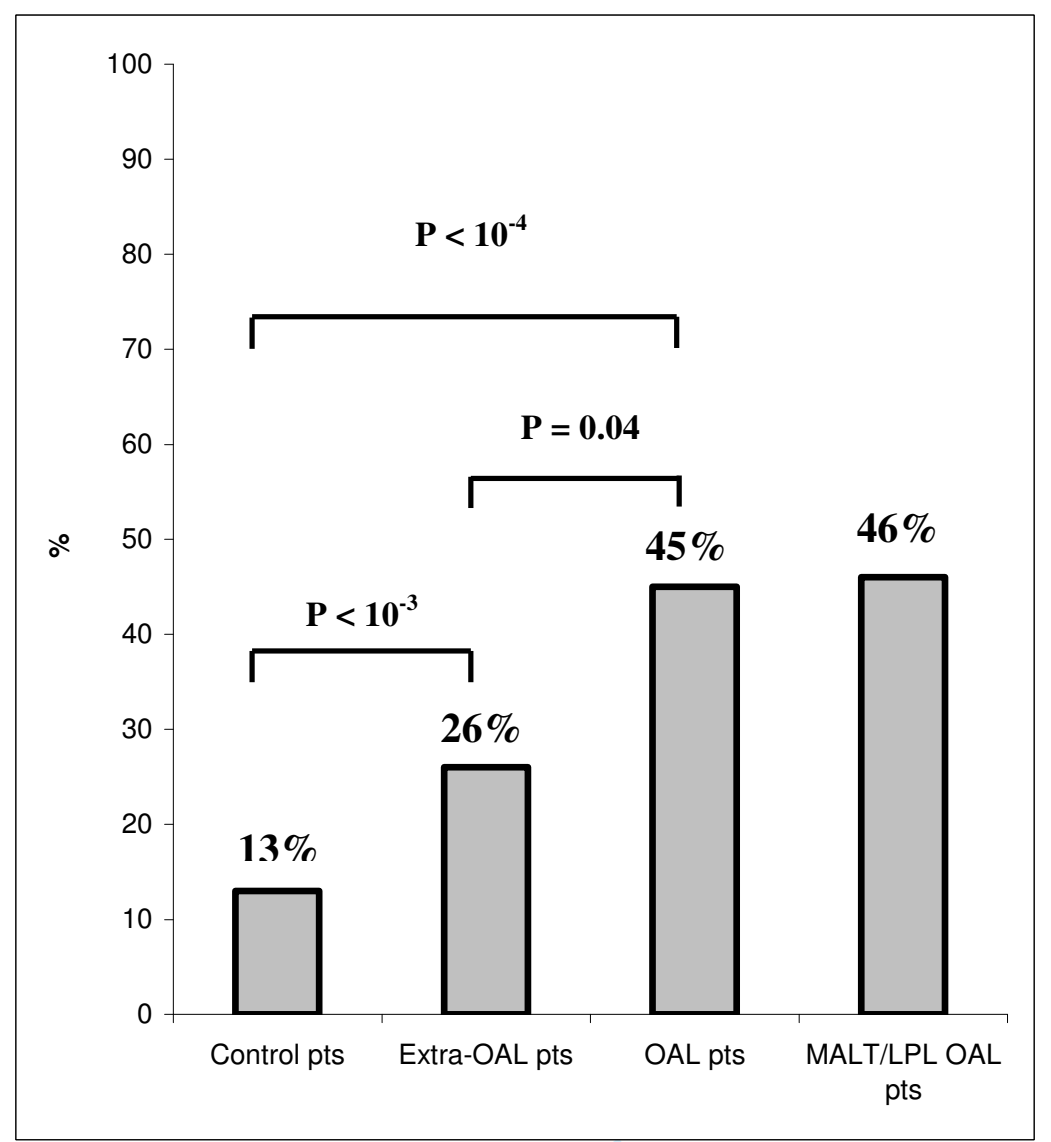

